\title{
Molecular Cloning, Transcriptional Profiling, Subcellular Localization, and miRNA-Binding Site Analysis of Six SCL9 Genes in Poplar
}

\author{
Meiqi Zhao ${ }^{1}$, Lei Xuan ${ }^{2}$, Haoran Qi ${ }^{1}$, Tengfei Shen ${ }^{1}$ and Meng Xu ${ }^{1, * *(1)}$ \\ 1 Key Laboratory of Forest Genetics and Biotechnology of Ministry of Education, Co-Innovation Center for \\ Sustainable Forestry in Southern China, Nanjing Forestry University, Nanjing 210037, China; \\ Zmq@njfu.edu.cn (M.Z.); HaoranQi@njfu.edu.cn (H.Q.); stf.njfu@gmail.com (T.S.) \\ 2 Institute of Botany, Jiangsu Province and Chinese Academy of Sciences (Nanjing Botanical Garden Mem, Sun \\ Yat-Sen), Nanjing 210014, China; 13851991791@163.com \\ * Correspondence: xum@njfu.edu.cn; Tel.: +86-150-9430-7586
}

Citation: Zhao, M.; Xuan, L.; Qi, H.; Shen, T.; Xu, M. Molecular Cloning, Transcriptional Profiling, Subcellular Localization, and miRNA-Binding Site Analysis of Six SCL9 Genes in Poplar. Plants 2021, 10, 1338. https:// doi.org/10.3390/plants10071338

Academic Editor: Ioannis

Ganopoulos

Received: 8 June 2021

Accepted: 27 June 2021

Published: 30 June 2021

Publisher's Note: MDPI stays neutral with regard to jurisdictional claims in published maps and institutional affiliations.

Copyright: () 2021 by the authors. Licensee MDPI, Basel, Switzerland. This article is an open access article distributed under the terms and conditions of the Creative Commons Attribution (CC BY) license (https:// creativecommons.org/licenses/by/ $4.0 /)$.

\begin{abstract}
The SCL9 subfamily is a key member of the GRAS family that regulates plant development and stress responses. Nevertheless, the functional role of these genes in the growth and development of poplar still unclear. Here, we reported the six SCL9 genes, which were found to be differentially expressed during poplar adventitious root formation. The full-length sequences of PeSCL9 genes of 'Nanlin895' poplar (Populus deltoids $\times$ Populus euramericana) were cloned by the RACE technique All PeSCL9 genes lacked introns. RT-qPCR revealed that PeSCL9 genes displayed a dynamic expression pattern in the adventitious root of poplar, according to RT-qPCR data. A series of comprehensive genes characteristics analysis were carried out for six genes by bioinformation. Meanwhile, transient expression analysis of the Populus protoplasts showed that all the PeSCL9 proteins were localized in the nucleus. In addition, the degradome and sRNA of 'Nanlin895' poplar in combination were used to predict miRNAs that regulate PeSCL9. It was found that miR396a and miR396c may affect PeSCL9 expression via cleavage, which was further verified by a transient expression experiment in Populus protoplasts. Overall, the development of poplar adventitious root and other tissues was closely related to these six SCL9 genes, and they serve as a starting point for further research into the mechanisms regulating poplar growth and development.
\end{abstract}

Keywords: 'Nanlin895' poplar; microRNA396; SCL9 subfamily; subcellular localization; adventitious root

\section{Introduction}

Poplar is the common name for species of Populus L., members of the Salicaceae, which are mainly distributed in the north temperate zone and cold temperate regions. Poplars are an important fast-growing industrial timber species in the mid-latitude plain, and these trees are also widely cultivated $t$ worldwide due to their ecological and economic benefits [1]. On the other hand, poplar, is also a model tree for the study of basic forest biology and an ideal choice for the study of the molecular basis of complex forest traits. Poplar was the first woody perennial plant to undergo complete genome sequencing. It easily propagates asexually and grows rapidly. The genetic transformation system is relatively well established for poplar, and research on the functional genomics of these trees has a good foundation. The regulation of some key functional genes involved in growth and development was preliminarily revealed [2-6]. Some microRNAs (miRNAs) are involved in morphogenesis, secondary metabolism, and stress response via the targeted cleavage of protein-coding genes [7-9]. However, the progress to date is only the beginning, and there are still many basic issues to be further studied. Forest plants have more complex organogenesis and stress response mechanisms than herbaceous plants, and fine mapping 
and functional identification of the genes related to growth, development, and stress adaptability in these species still require further research.

The GRAS family is an ancient and unique transcription factor (TF) family in plants, and it is named for three genes: gibberellic acid insensitive (GAI) [10], repressor of GA1-3 mutant (RGA) [11] and scarecrow (SCR) [12]. GRAS proteins are generally composed of 400-770 amino acids that exhibit, a high degree of similarity at the carboxyl terminus. Leucine heptad repeat I (LHRI), VHIID, leucine heptad repeat II (LHRII), PFYRE and SAW are the five structural domains [13]. The nuclear localization signal (NLS) of most members of this family exists in the LHRI region, and the protein-DNA interactions are mediated by the VHIID motif [13]. The LXXLL motif, which exists in the LHRII region and mediates the binding of steroid receptor coactivator complexes to nuclear receptors [14]. Only the proline residues are highly conserved in the PFYRE, which is separated into three parts: P, FY, and RE. R-E, W-G, and W-W are three highly conserved amino acid residue pairs that compose the SAW motif [15-17]. The GRAS family participates in several aspects of plant organogenesis, morphogenesis, plant growth, development, and stress $[18,19]$. Based on the characteristics of the protein domains, the 33 Arabidopsis GRAS proteins could be divided into eight branches: LISCL (SCL9), HAM, PAT1, Scarecrow-like 3 (SCL3), DELLA, SCR, SHR, and LS [20]. AtPAT1 is involved in the signal transduction of photosensitive pigments [21]. The DELLA protein is a central element in the GA signaling pathway that suppresses the signaling and development of plants by the negative regulation of GA signaling, while the SCL3 can weaken the DELLA repressor in the root endothelium, and then positively regulate the downstream pathway of GA signaling, which is participates in the development of roots and aboveground organs [22,23]. SCL3 competitively inhibits the interaction between DELLA and IDD (INDETERMINATE DOMAIN) protein, thereby inhibiting the expression of downstream genes [24]. SCR/SHR transcription factors regulate the radial development pattern of roots and the specialization of quiescent center properties [16,25-27]. LISCL (Lilium longiflorum Scarecrow-like) is a GRAS protein in lily. Its amino-terminal has strong transcriptional activation activity, and it is mainly expressed in the prophase of meiosis in anthers [28]. Notably, the number of genes belonging to the SCL9 subfamily is significantly greater than other subfamilies in most species [29], and the biological function of the SCL9 subfamily members are rarely reported. The overexpression of one gene encoding the SCL9 subfamily, OsGRAS23, can significantly improve the drought resistance and antioxidant capacity of rice [30]. Silencing of the TaSCL14 gene resulted in slow plant growth, leaf senescence, and lower tolerance to photooxidative stress in wheat [31]. AtSCL14 and glutathione GRX480/ROXY19 compete for combinations with the TGAII transcription factor to mediate the activation and inhibition of detoxification responses, respectively, in Arabidopsis thaliana [32-34]. Some small RNAs also interact with GRAS members to regulate growth and development [35-38].

The 106 GRAS TF members predicted in the poplar genome belong to 13 subfamilies [39], each of which is critical for poplar growth and development. To date, we have studied and reported the HAM [40], PAT1 [41], DELLA [42], SCR and SHR [43] genes of the GRAS family, and verified some of their roles. The SCL9 subfamily is a great member of the GRAS family, which has been many studies on stress and development in diverse plants. However, there are relatively few reports on molecular biology and functions of the genes of the poplar SCL9 subfamily. In the present study, by screened from the genome sequencing information of poplar, we found that six SCL9 genes had a different expression level during adventitious root development. We cloned and identified the full-length of six PeSCL9 genes. Meanwhile, the SCL9 genes and their protein sequences of 'Nanlin895' poplar ( $P$ deltoids $\times$ euramericana) were analyzed by bioinformatics approaches. The transcriptional regulation relationship between miR396a/c and PeSCL9 was verified by combining the degradome with the Populus protoplast transient expression system. Our results indicated SCL9 subfamily had a function in the development in poplar, and supply the research blank. This research provides a basic understanding for further functional studies of SCL9 genes in plants. 


\section{Results}

\subsection{Gene Structure and Promoter Analysis of SCL9 Genes}

Six SCL9 family gene members that regulate the adventitious root development of Populus were screened out based on entire genome sequencing information of poplar and the expression profile of rooting poplar cuttings gene chip. The full-length sequences of six poplar SCL9 branch genes were obtained by 3' RACE and 5' RACE procedures, and the genes were named PeSCL9, PeSCL14-1, PeSCL14-2, PeSCL14-3, PeSCL30-1, and PeSCL30-2, respectively, based on phylogenetic analysis. The basic characteristics of genes are enumerated in Table S1. The sequence length of genes ranged from 3005 bp (PeSCL14-3) to $2494 \mathrm{bp}$ (PeSCL30-1). The length of the open reading frames (ORFs) of genes were within the scope of 1974 bp (PeSCL30-1) to 2280 bp (PeSCL14-1, PeSCL14-2, PeSCL14-3), and encoded polypeptides of 657-759 amino acids. The primary structures of the six proteins were predicted by ExPASy ProtParma. Their molecular weights were 74.82-85.52 kDa, and the theoretical isoelectric points were all less than seven, which indicates that the proteins were weakly acidic. The grand average of hydropathy (GRAVY) varied from -0.622 (PeSCL30-2) to -0.449 (PeSCL9). The secondary structures of the six proteins were tested by the self-optimized prediction method with alignment (SOPMA), and different results were obtained for each component. Among them, the contents of $\alpha$ helix structures and $\beta$ corners in PeSCL30-1 were higher and accounted for $42.77 \%$ and $4.11 \%$, respectively. The content of extended chains in PeSCL9 was $9.30 \%$, and the content of random coils in PeSCL14-3 was 49.67\% (Additional File: Table S1). Moreover, genomic and cDNA sequence comparisons revealed that all six SCL9 genes were all intron-free.

The cis-elements must be highlighted as crucial in the transcriptional regulation of gene expression. 'Nanlin895' poplar is closely related to Populus deltoides, and the genome was used as the reference genome to extract the $2000 \mathrm{bp}$ upstream sequence of the start codon in the promoters of each gene from the P. deltoides genome (v.2.1). We used the PlantCare website to predict the cis-elements. A series of crucial cis-elements were found (Figure 1; Additional File: Table S2), including light response, auxin response, gibberellin response, abscisic acid response, MeJA response, and low-temperature response elements, which indicated that the SCL9 genes regulate different biological processes.
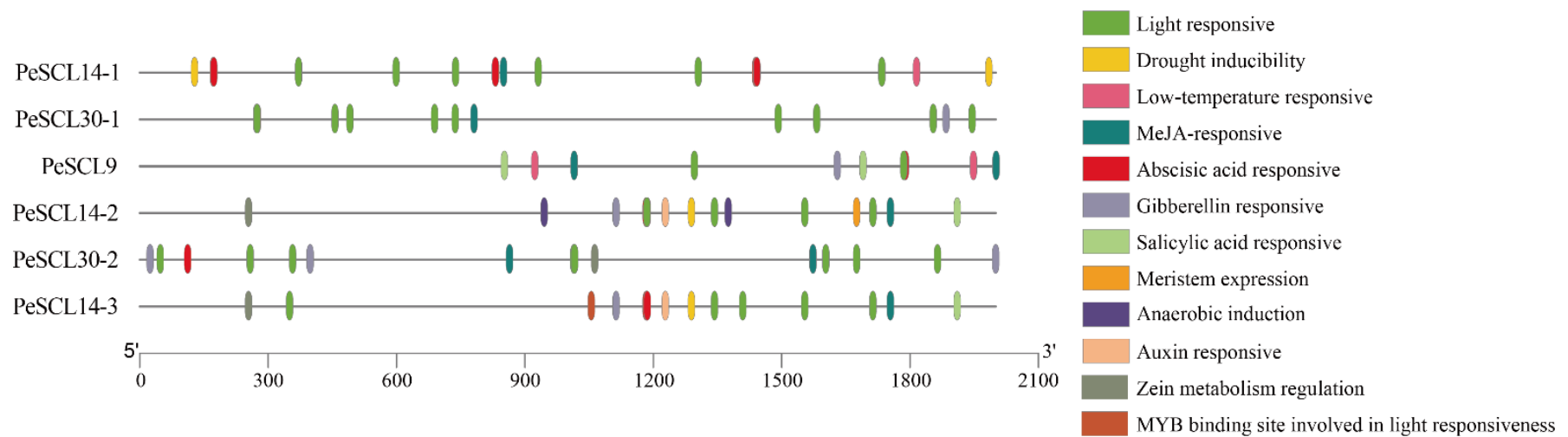

Figure 1. Cis-elements in the PeSCL9 genes promoter regions. Different colors represent different cis-elements.

\subsection{Multiple Sequence Alignment, Phylogenetic Analysis, and Motif Composition of PeSCL9 Genes}

To further study PeSCL9 protein domains, we compared the GRAS domains of different species. The results revealed that the C-terminus of the proteins encoded by these six genes was consistent with the structure of 16 SCL9 subfamily proteins, and all contained LHRI, LHRII, VHIID, PFYRE and SAW domains specific to the GRAS family. No DELLA domain was found at the amino terminus (Figure 2), and these domains were distributed in the same order. 

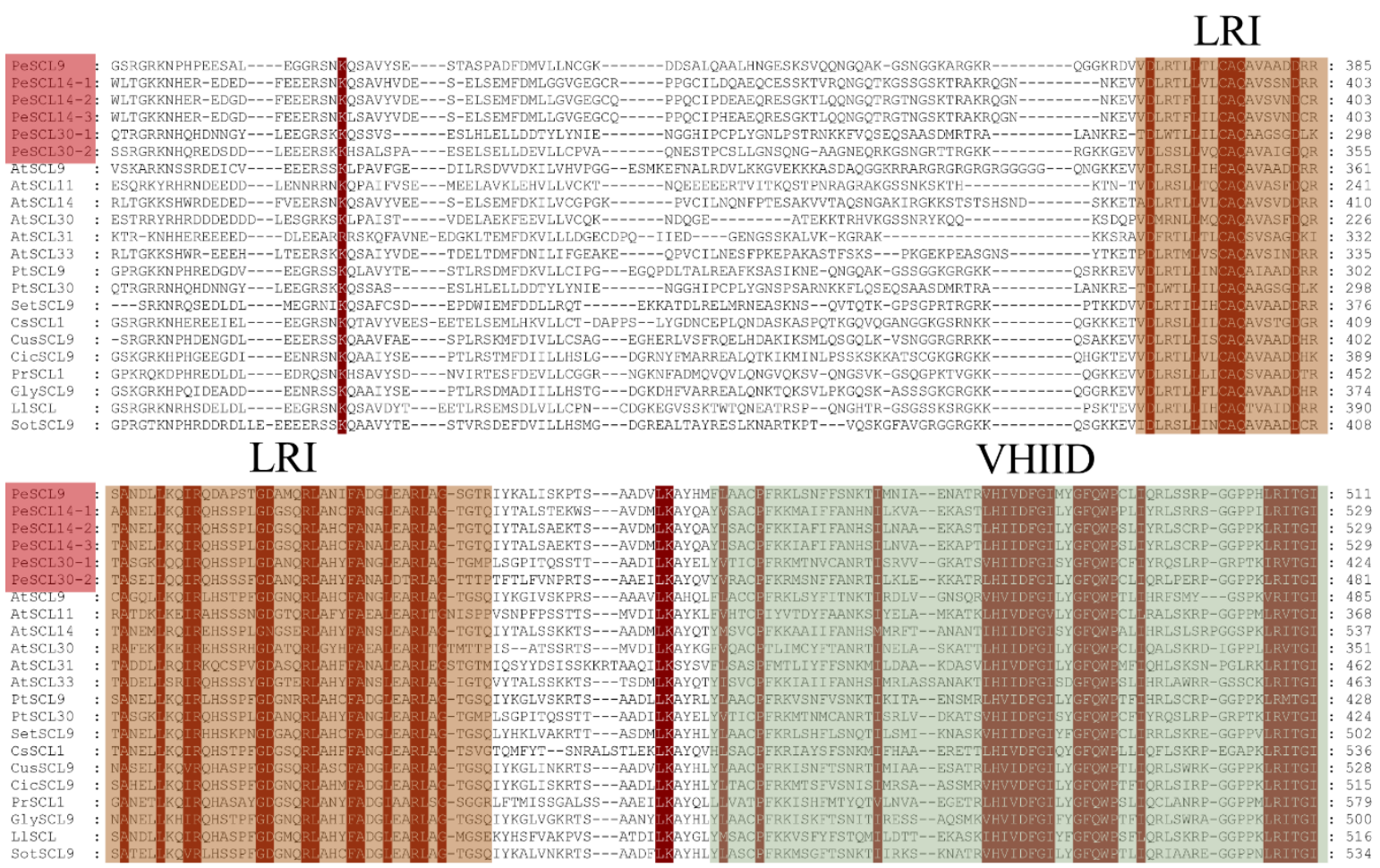

\section{LRII}
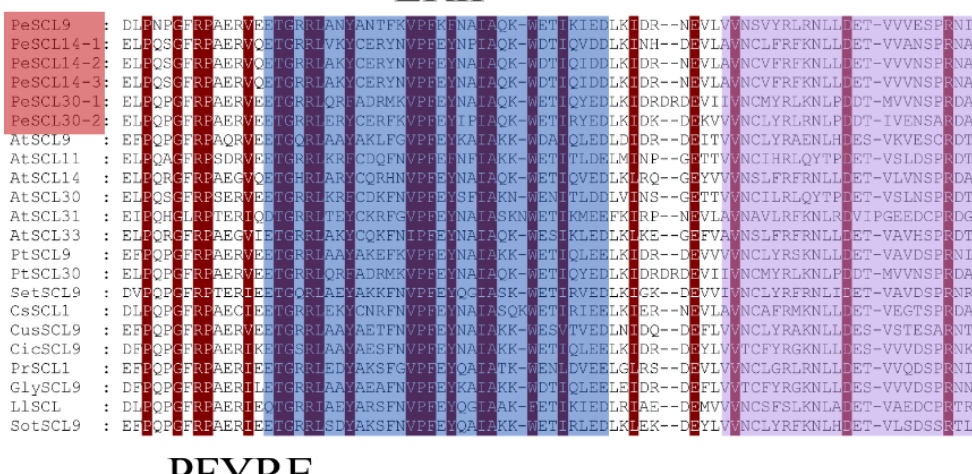

\section{PFYRE}

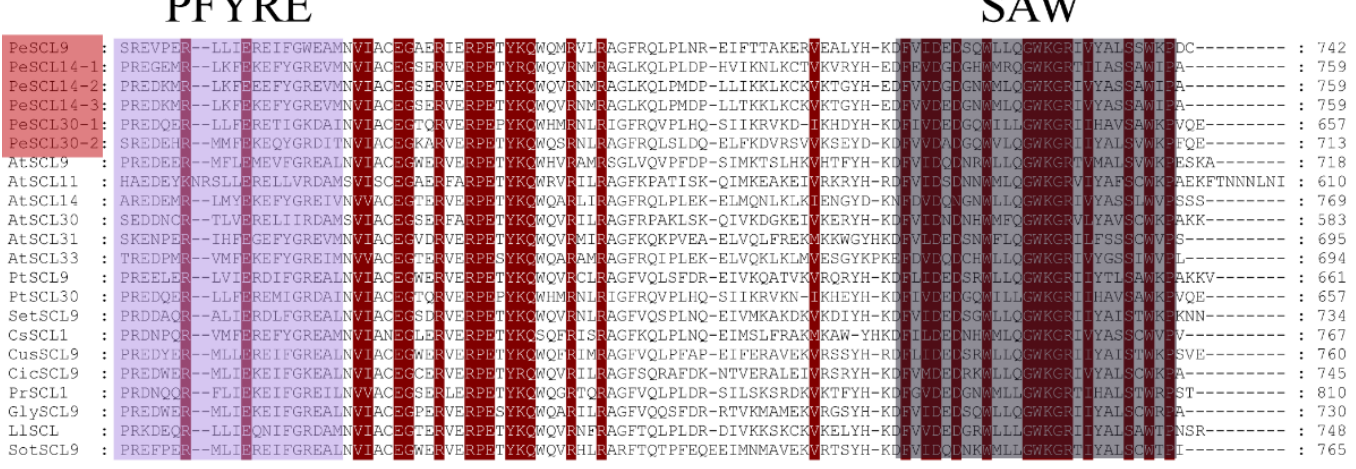

Figure 2. Sequence analysis of SCL9 proteins. ClustalX (v.2.1) alignment of the amino acid sequences of poplar SCL9, Arabidopsis thaliana SCL9, and other SCL9 proteins. The GRAS domains are indicated in different colors.

The phylogenetic relationships of PeSCL9 proteins were analyzed via alignment of the GRAS domain, represented by the GRAS domains of 16 SCL9 TFs from 10 species, including Arabidopsis thaliana and Castanea sativa. The results revealed that these six proteins were grouped into three clades. The SCL9 subfamily of PeSCL9 proteins and Arabidopsis thaliana, Solanum tuberosum and other species were clustered in Clade 1, and PeSCL30-1 and PeSCL30-2 are clustered in Arabidopsis thaliana. The SCL30 gene from Populus trichocarpa and other species were concentrated in Clade 2, and the homology of PeSCL14-1, PeSCL14- 
2, and PeSCL14-3 is very high. As in Arabidopsis thaliana, AtSCL14, AtSCL33 and other proteins were clustered in Clade 3 (Figure $3 \mathrm{a}$ ), and the results were essentially identical to the phylogenetic analysis, with differences between groups but similarities within groups. The motifs of 22 SCL9 proteins were examined by MEME online to learn more about the SCL9 proteins characteristic region. Twenty distinct MEME motifs (designated motifs 1-20) were discovered (Figure 3b; Additional File: Table S3). The SCL9 proteins in the same evolutionary lineage generally had the same motif composition (e.g., PeSCL30-1 and PtSCL30), which suggested that similar functions are the result of genes from the same evolutionary lineage.

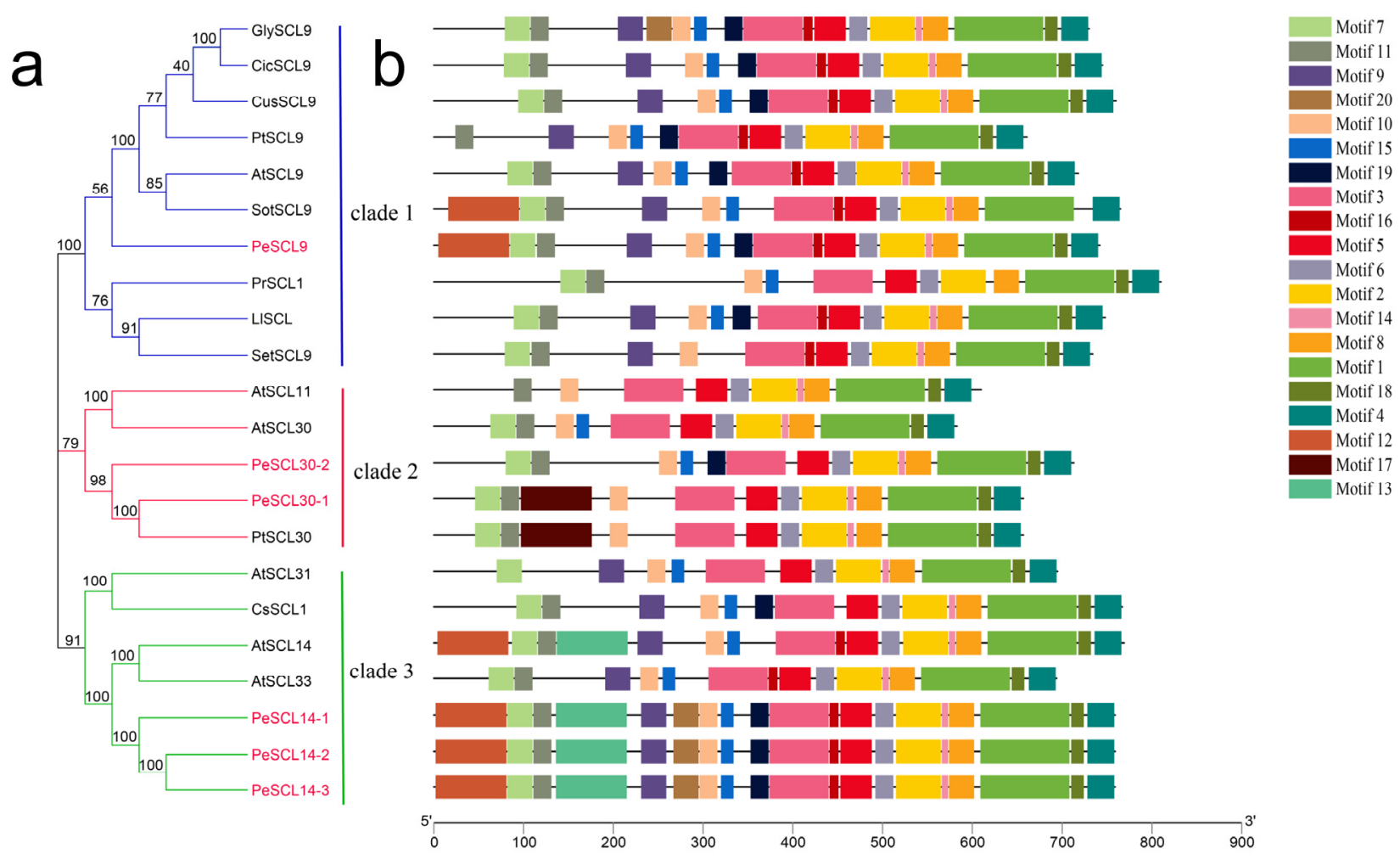

Figure 3. Phylogenetic relationship and gene structure of SCL9 proteins from different plant species. (a) The phylogenetic tree was generated based on the multiple sequence alignment of the 22 SCL9 proteins by using neighbor joining (NJ) method (bootstrap value $=1000)$. PeSCL9 proteins are marked in red; $(\mathbf{b})$ conserved domains or motifs in the SCL9 proteins. The sequence information for each motif is provided in the Additional File: Table S3.

\subsection{Subcellular Localization of SCL9 Proteins}

To understand the function of SCL9 proteins, we further analyzed the subcellular localization of six PeSCL9 genes using GFP as a tag. The positive control spread throughout entire cells, and the six fusion proteins in the SCL9 branch all produced green fluorescence in the nuclear region, which indicated that the proteins encoded by the six genes in this study were all localized in the nucleus. These findings suggest that these genes have a transcriptional regulatory function in the growth of poplar (Figure 4). 


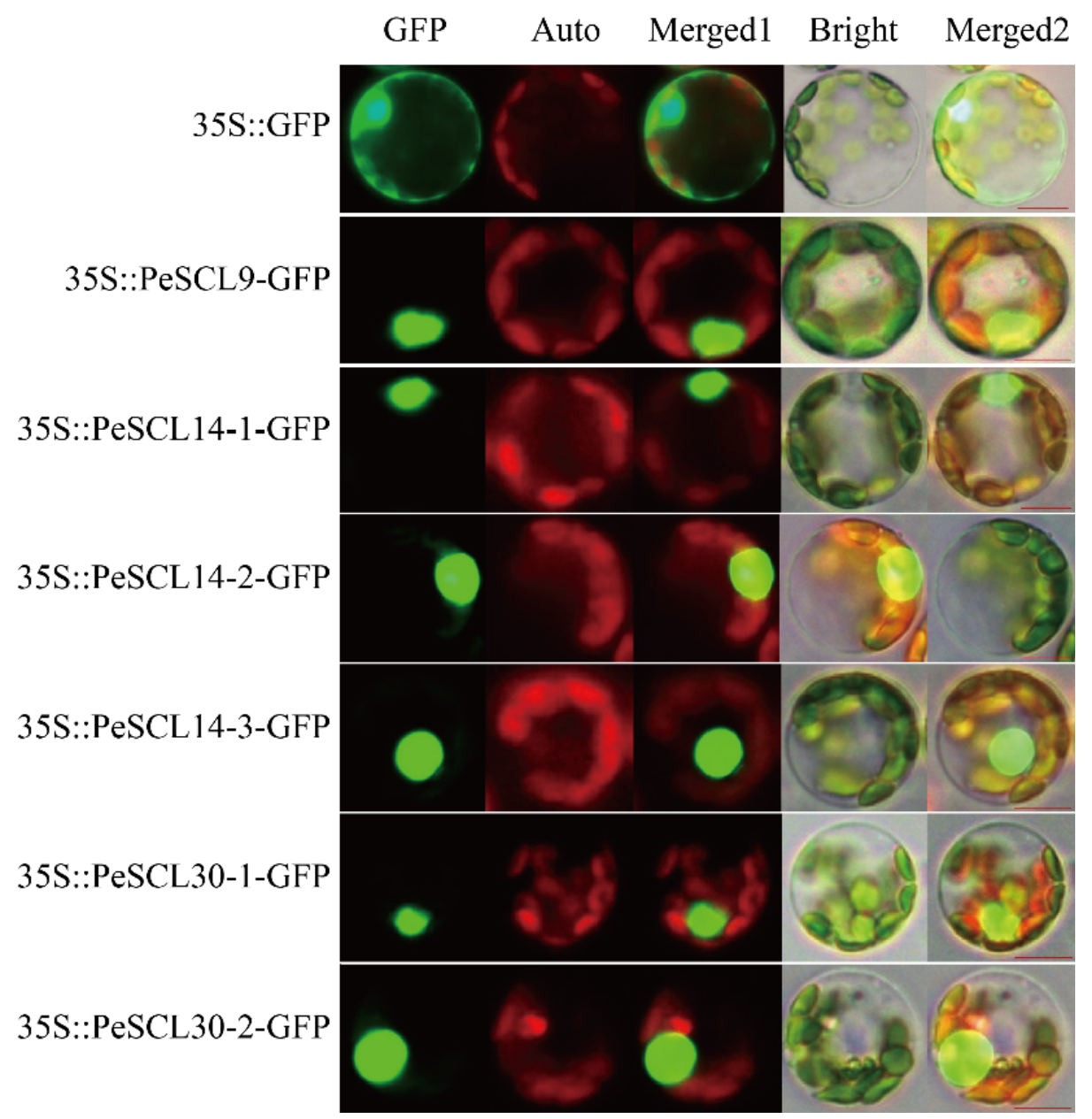

Figure 4. Subcellular localization of SCL9 branch genes in Populus mesophyll protoplasts. Green fluorescence protein (GFP), chlorophyll autofluorescence (Auto), Merged 1, bright and Merged 2 images are shown. Scale bar $=10 \mu \mathrm{m}$. The 35S::GFP fusion was used as a positive control protein and was detected in the nucleus and cytoplasm in Populus protoplasts.

\subsection{Expression Patterns of PeSCL9 Genes}

To verify the expression of PeSCL9 genes during the development of Populus, RT-qPCR was performed to analyze the expression of genes in diverse tissues and organs of poplar and at different stages of root development (Figure 5). Intriguingly, the expression of PeSCL30-1 was almost nonexistent in leaves and stems after four weeks, and the expression of PeSCL14-1 was highest in roots. The expression levels of the other four genes were the highest in leaves and the lowest in stems. However, the overall expression level of PeSCL141 was lower than the other genes. In addition, these genes also showed diverse expression trends at different developmental stages of roots. The expression trend of PeSCL14-1 gene in roots at four weekly developmental stages $(1 \mathrm{~W}, 2 \mathrm{~W}, 3 \mathrm{~W}, 4 \mathrm{~W})$ was "decreased first and then increased", with the highest expression level at $1 \mathrm{~W}$. The remaining five genes were "increased first and then decreased". The expression of PeSCL30-1 and PeSCL30-2 was the highest at $2 \mathrm{~W}$, and the expression of PeSCL9, PeSCL14-2 and PeSCL14-3 was the highest at $3 \mathrm{~W}$. These results indicated that these six genes showed different expression patterns in different tissues and different developmental stages of poplar roots. 

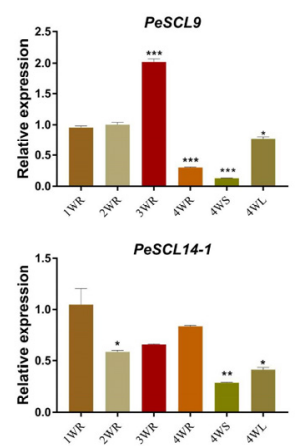
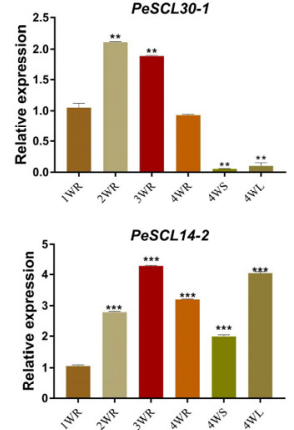
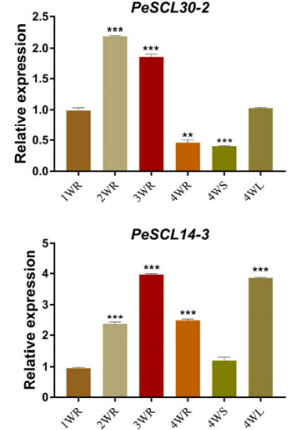

Figure 5. Expression patterns of SCL9 subfamily genes at different time points and tissues of Populus. Temporal and spatial expression patterns of poplar SCL9 genes by real-time RT-PCR. The Y-axis represents relative quantitation and the $X$-axis represents different time points/tissues. The error bars represent the mean $\pm \mathrm{SE}$, where $n=3$. Statistical significance of differences was determined by the Student's $t$ test $\left({ }^{*} p<0.05,{ }^{* *} p<0.01,{ }^{* * *} p<0.001\right.$, compare to $\left.1 \mathrm{WR}\right)$.

\subsection{MiR396a/c-Directed Targeting of PeSCL9 Genes in Populus}

According to the sRNA database of 'Nanlin895' poplar, we used the psRNATarget website to search for potential miRNAs that may regulate PeSCL9 genes. We identified 36 potential miRNAs that may regulate target genes by cleavage using a mismatch score of 4.0 (Additional File: Table S4). The cleavage sites of PeSCL9 mRNAs were further identified based on the degradome from our laboratory. Cleaveland 4 was used to predict the cleavage sites. To improve the prediction accuracy, only miRNAs with category scores of $0-2.0$ were considered candidate miRNAs. The results showed that miR396a could target PeSCL14-1 and PeSCL14-2, and miR396c regulate PeSCL14-3 (Figure 6). The cleavage sites were at 767, 823 and 855, respectively. Remarkably, mature miR396a-5p and miR396c-5p were highly homologous, which suggests regulation of the same target genes.

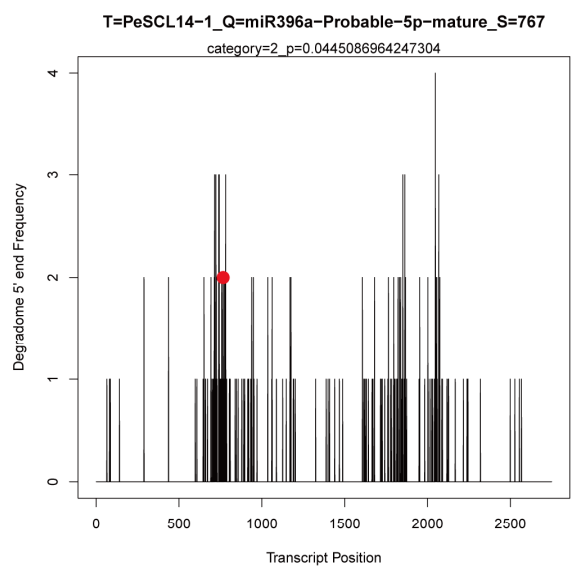

5' CAgundangagagguguagaggaA 3' PeSCL14-1 |||||||||| O ||||| || |||

3' GUCAAGUUCUUUCGACA - - -CCUU 5' ptc-miR396a

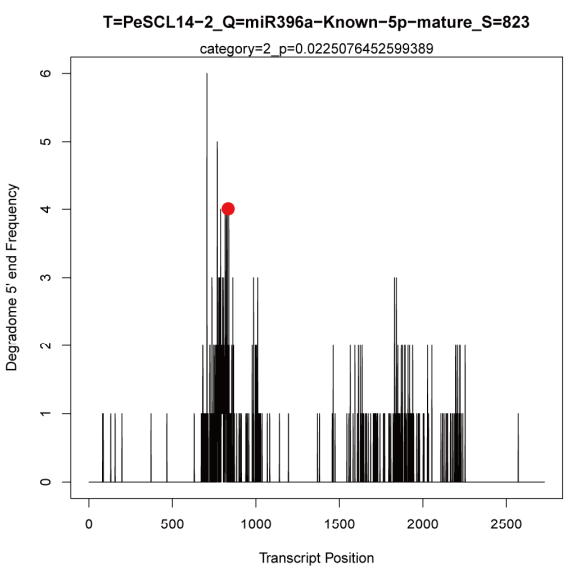

5' CAguUdaAgagagguguagaggaA 3' PeSCL14-2 | | | | | || || | o | || | | | | | 3' GUCAAGUUCUUUCGACA - - -CCUU 5' ptc-miR396a

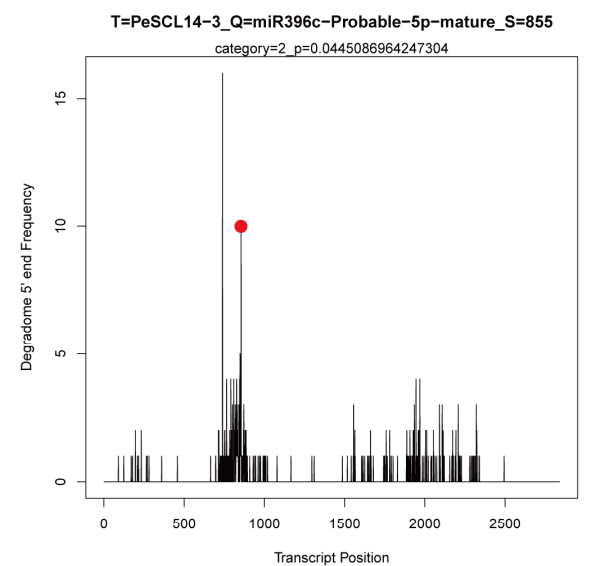

5' CAguudaagagagguguagaggaA 3' PeSCL14-3

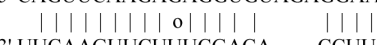
3' UUCAAGUUCUUUCGACA - - -CCUU 5' ptc-miR396c

Figure 6. Target plots (t-plots) of representative Pe-miRNA targets confirmed by degradome sequencing.

To detect whether the miR396a/c target genes were consistent with the degradome sequencing results (Figure 6), we studied miR396 regulation of target genes by the transient expression system of poplar [44] and measured the expression levels of three target genes after the transient overexpression of miR396a/c by RT-qPCR. The control check (CK) was the normal protoplast without any plasmid transfer. The expression levels of miR396a in protoplasts transfected with 35S::miR396a and 35S::miR396c were significantly higher than the CK. As expected, target genes expression were reduced in 35S::miR396a and 35S::miR396c compared to the control. Strikingly, transient overexpression of miR396a 
reduced the expression of PeSCL14-2 by approximately 10 fold (Figure 7). These results confirmed that miR396 targeted PeSCL9 genes.

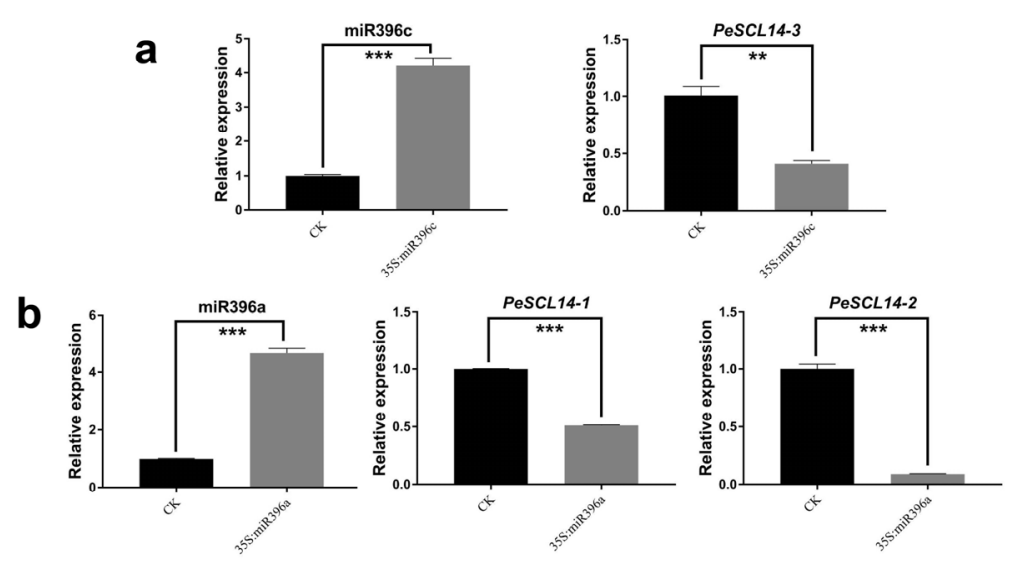

Figure 7. The expression pattern of miR396 and its target gene PeSCL9 in Populus protoplasts. The $Y$-axis represents relative quantitation and the $X$-axis represents different expression vectors. (a) Overexpress of miR396c leads to a decrease in the expression of PeSCL14-3; and (b) overexpress of miR396a leads to a decrease in the expression of PeSCL14-1 and PeSCL14-2. The error bars represent the mean \pm SE, where $n=3$. Statistical significance of differences was determined by the Student's $t$ test ${ }^{* *} p<0.01,{ }^{* * *} p<0.001$, compared to control).

\section{Discussion}

GRAS is a specific and widespread TF family in plants, and is involved in many processes of plant growth and development. The genome-wide identification of GRAS family members of diverse species has been gradually completed. The amount of GRAS genes in Populus is approximately two to three times the number in rice and Arabidopsis thaliana. Notably, 22 percent of GRAS genes in Populus are produced by the combined mechanism of tandem and segmental replications, compared to just eight percent in Arabidopsis thaliana and rice, which suggests that this distinction may underlie the fast proliferation of the GRAS family in Populus [39]. Species genetic differences and the rate of evolution are linked to a variety of causes, and environmental changes can also have a strong impact on plants [45]. Only a small number of GRAS genes in poplar have been studied [46,47]. We previously reported that HAM [40], SHR/SCR [43], DELLA [42], and PAT1 [41] transcription factors may be involved in the growth and development of adventitious root, stems, and leaves of poplar. SCL9 is a member of the GRAS family, and it was the first GRAS protein to be implicated in the direct control of specific gene expression. The amino terminus of the LISCL gene, a new GRAS gene in lily, bears no resemblance to the SCR protein, and neither molecule has the DELLA domain [28]. Therefore, these authors speculated that the LISCL gene had specific functions, and demonstrated that the N-terminus of the LISCL protein had significant transcriptional activation ability and played a role in anther meiosis. Six SCL9 genes were cloned from the 'Nanlin895' poplar to investigate the role of the SCL9 subfamily in poplar. Sequence alignment showed that these genes were similar to the SCL9 subfamily of Arabidopsis thaliana and Castanea sativa, and contained conserved GRAS domains [13]. Phylogenetic analysis divided these six genes into three clades. In the meanwhile, there appeared to be a similar motif structure in each clade, which indicated the same function in plant development. For example, previous studies have shown that CsSCL1 and PrSCL1 genes are mainly expressed in the roots, and they perform key functions in the primary stage of adventitious root formation. GRAS proteins from these two distant tree species exhibit similar sequences and functions, which indicated that these two proteins have conserved functions in the process of adventitious root formation [48]. AtSCL14 ameliorates the stress of photooxidation [49]. The PeSCL14-1, PeSCL14-2, and PeSCL14-3 genes were highly homologous with AtSCL14 and CsSCL1, which suggests their involvement in the establishment of the poplar root meristem and the 
detoxification reaction. The six genes cloned in the present study had the same domain as LISCL, which suggests their involvement in the meiosis process in poplar.

Cis-elements are essential regulators of plant transcription in response to abiotic stress and plant hormone responses $[50,51]$. Previous studies found that the domain of LISCL was related to transcriptional activation or co-activation in response to various signals [52]. The present study examined cis-elements in the promoter region of the PeSCL9 genes. At least one cis-element related to plant hormones was found in each gene (Figure 3 ). The PeSCL14-2 and PeSCL14-3 genes had five hormone-responsive elements, which were highly homologous and suggest that these genes play key roles in the response of poplar to hormones. Only PeSCL14-1 and PeSCL9 were involved in the low-temperature response. GRAS proteins, such as SIGRAS40 [53], OsGRAS23 [30], and BnGRAS25 [54], play roles in plant and abiotic stresses. Therefore, these genes likely regulate abiotic stress responses and hormones. In addition, our subcellular localization results showed that the proteins encoded by six SCL9 genes were all localized in the nucleus, which suggests a role for these genes in transcriptional regulation.

Previous studies demonstrated that SCL9 genes were involved in adventitious root formation and other regulatory processes [55]. Among them, ZmGRAS25 is highly expressed in maize primary roots and may be involved in the formation of the maize root system [56]. The expression levels of the SCL9 genes were the highest in the roots of Tartary buckwheat [17]. The results suggest that the SCL9 subfamily may play a very important role in the growth and development of plant roots. We hypothesized that these six SCL9 genes were involved in adventitious root formation. Therefore, RT-qPCR was used to measure the expression of these six genes in diverse tissues of poplar. The expression trends of four genes were consistent in growing roots, stems and leaves for four weeks, but PeSCL30-1 and PeSCL14-1 expression were not consistent. The expression levels of these genes were higher in leaves and the lowest in stems. Measurement of the expression levels of these genes at different periods of root development showed that the expression levels of PeSCL14-1 were high in the early stage (1 WR) and maturation stage (4 WR) of adventitious root development. The remaining genes were expressed during early and mid-term root development, with expression peaking at two to three weeks then decreasing.

MiRNAs play core roles in embryogenesis, root and leaf development, and the responses to biotic and abiotic stress [57,58]. MiR396 is a highly conserved family of plant miRNAs that are found in all land plants [59]. MiR396 plays important role in many aspects of plants. MiR396a-3p/5p and miR396b are mainly expressed in fruits and make fruits larger and play an important role in fruit yield and crop improvement [60]. MiR159 and miR396 regulate floral characteristics and timing in dicotyledons and monocotyledons [61]. Meanwhile, miR396 inhibits the expression of growth-regulating factors (GRFs) to regulate the transition of root stem cells to transitional proliferating cells, and it participates in the process of root development [62]. The present study examined the relationship between $\mathrm{miR396a/c}$ and PeSCL9 genes and found two miRNAs that may regulate the expression of three PeSCL9 genes by cleavage based on analysis of the sRNA and degradome data. MIR396a matched PeSCL14-1 and PeSCL14-2, and miR396c matched PeSCL14-3. To further confirm the regulation of PeSCL9 and miR396a/c, the expression levels of target genes were analyzed after transient overexpression of $\mathrm{miR} 396 \mathrm{a} / \mathrm{c}$, and the results indicated a decrease in all of the target genes to varying degrees. Therefore, we speculated that miR396 participated in plant growth and development via the cleavage of PeSCL9 genes.

Populus is the most widely distributed tree. It is an economically important tree. Some studies used transcriptome sequencing, genome resequencing and bioinformatics methods to identify genes, which are associated with a lignin pathway. The associated genetic strategy was used to analyze 124 additional SNP sites on the formation of wood formation, dominant and upper genetic effects, and constructed lncRNA-miRNA-mRNA genetic regulation network [63]. In addition, a total of 462 SNPs were found from poplar, which will be very useful for assessment of breeding populations [64]. In this study, we 
found miR396 decreased the expression level of SCL9 genes, which indicated miRNAs play a pivotal role in the regulation at the transcriptional level through genetic interaction.

In present, the specific function of SCL9 subfamily in plants is still in basic research. With the development of plant genomics, we should make full use of the information to solve the existing biological problems, so as to achieve the purpose of improving the traits of tree species [65], gene editing and transgenics can also be used to study the function of genes. In addition, miRNA, as an important non-coding RNA in a class of organisms, is a key part of the gene regulation network. We can study the interaction with target genes by means of mutated miRNA binding sites, dual-luciferase reporter assay system, 5'-RLM-RACE, etc.

\section{Materials and Methods}

\subsection{Plant Materials and Growth Conditions}

All sampled plantlets of 'Nanlin895' poplar were placed in a light incubator $(16 / 8 \mathrm{~h}$ light/dark, temperature of $25 / 18{ }^{\circ} \mathrm{C}, 70 \%$ relative humidity) on Murashige and Skoog (MS) medium ( $\mathrm{pH} 5.8$ ). The roots at one week (1 WR), two weeks ( $2 \mathrm{WR})$, three weeks ( $3 \mathrm{WR}$ ) and four weeks (4 WR), the stems (4 WS), and the leaves $(4 \mathrm{WL})$ were used as tissue materials. The samples were stored at $-80^{\circ} \mathrm{C}$ prior to RNA extraction to determine the degree of expression in various organs and developmental periods. The leaves of tissue culture seedlings grown for 40 days were used for protoplast separation and transient transformation.

\subsection{RNA Isolation and Gene Expression Analysis}

Total RNA was isolated from poplar using RNeasy Plant Mini Kit (Qiagen, Hilden, Germany) according to the manufacturer's instructions, and the RNA was purified by DNase I (Qiagen, Hilden, Germany). The concentration, purity (A260/280 $=1.8-2.1$ ) and integrity of total RNA were measured using a Nanodrop 2000c spectrophotometer (Thermo Fisher, Waltham, MA, USA) and 1\% agarose gel electrophoresis, respectively. PrimeScript ${ }^{\mathrm{TM}}$ RT Master Mix was used to reverse-transcribe cDNA (Takara, Otsu, Japan). According to the manufacturer's instructions of the Mir-X miRNA First-strand Synthesis Kit (Takara, Otsu, Japan), $1 \mu \mathrm{g}$ of miRNA and other RNA molecules were transformed into cDNA. Real-time quantitative primers were designed using Oligo7 software. The elongation factor 1 alpha (EF1 $\alpha$ ) gene (GenBank Accession Number: AJ536671) [66] was used for normalization. Real-time PCR was conducted using a ViiA ${ }^{\mathrm{TM}} 7$ Real-time PCR System (Applied Biosystems, New York, NY, USA) with PowerUP ${ }^{\mathrm{TM}}$ SYBR $^{\mathrm{TM}}$ Green Master Mix (Thermo Fisher, Waltham, MA, USA). The real-time PCR system protocol was followed. The following reaction procedure was used: UDG activation at $50{ }^{\circ} \mathrm{C}$ for $2 \mathrm{~min}$, DualLock ${ }^{\mathrm{TM}}$ DNA polymerase at $95^{\circ} \mathrm{C}$ for $2 \mathrm{~min}, 40$ cycles of denaturation at $95^{\circ} \mathrm{C}$ for $15 \mathrm{~s}$, and annealing/extension at $60^{\circ} \mathrm{C}$ for $1 \mathrm{~min}$. The dissociation curve conditions (melt curve stage) were set at $95^{\circ} \mathrm{C}$ for $15 \mathrm{~s}, 6{ }^{\circ} \mathrm{C}$ for $1 \mathrm{~min}$, and $95^{\circ} \mathrm{C}$ for $15 \mathrm{~s}$. The specific mRQ3' primers and miRNA mature sequences (miR396a: UUCCACAGCUUUCUUGAACUG, miR396c: UUCCACAGCUUUCUUGAACUU) were used for real-time PCR. The reference genes and reaction system are described above. Each experiment had three technical replicates, and the relative quantitative analysis was performed using the $2^{-\triangle \Delta \mathrm{Ct}}$ method. All of the primer sequences are listed in Supplementary Table S5 (Additional File: Table S5).

\subsection{Gene Cloning of Full-Length PeSCL9 Genes}

Primers for 3'RACE and 5'RACE PCR amplification were constructed using the probe sequence from the poplar genome chip. The full-length sequence was amplified by nested PCR according to the operation instructions for the 3' Full Race Kit and 5' Full Race Kit (Takara, Otsu, Japan). The target fragment was recovered and purified using an Axygen gel extraction kit (Axygen, Central Avenue, CA, USA) after the PCR product was detected by $1 \%$ agarose gel electrophoresis. The isolated fragment was connected to the $\mathrm{pMD} 19-\mathrm{T}$ vector (Takara, Otsu, Japan) and transformed into TOP10 (Takara, Otsu, Japan). The positive 
clones were screened and sequenced for analysis. The 3' RACE and 5' RACE sequences were matched and spliced to obtain the full-length gene sequence. The same primers were used to amplify the predicted ORFs and genomic DNA sequences through the high-fidelity KOD enzyme (Takara, Otsu, Japan), and then the number and location of introns were determined by comparison. Supplementary Table S5 lists the primer sequences utilized in this investigation (Additional File: Table S5).

\subsection{Genes Sequence Analysis}

The NCBI ORF Finder (https: / / www.ncbi.nlm.nih.gov/orffinder/accessed on 5 October 2020) was used to predict the ORF sequences. The basic characteristics of the genes and amino acid composition of the proteins were analyzed by the ExPASy ProtParma website (https: / / web.expasy.org/protparam accessed on 5 October 2020). The online SOPMA program (https: / / npsa-prabi.ibcp.fr/cgi-bin/npsa_autmat.pl?page=/NPSA/ npsa_sopma.html accessed on 5 October 2020) was used to predict the secondary structure of amino acid sequences in October 2020. The GRAS domain was inferred from the Pfam database in October 2020 (http:/ / pfam.xfam.org/ accessed on 12 March 2021) and the E-value cut-off was 1e-5. The latest protein file of the Populus deltoides genome was downloaded from Phytozome (v.12.1) (https://phytozome.jgi.doe.gov/pz/portal.html accessed on 12 March 2021) and the 2000 bp sequences upstream of six genes were extracted in TBtools software (v.1.0971) [67] and submitted to the PlantCARE online database (http:/ / bioinformatics.psb.ugent.be/webtools/plantcare/HTML accessed on 16 March 2021) to predict cis-elements in the promoter region in March 2021 [68]. The TBtools program was used to draw the cis-elements of genes. The Plant Transcription Factor Database (http:/ / planttfdb.gao-lab.org/ accessed on 19 March 2021) was used to obtain the domain sequences of the GRAS proteins from Arabidopsis thaliana, Castanea sativ, and other plants. The protein sequences of the six genes discovered were compared to other plants using ClustalX (v.2.1) software. Then, MEGA X software was used to conduct phylogenetic analyses in November 2020, with the neighbor-joining (NJ) algorithm and 1000 bootstrap replicates [69]. GeneDoc (www.psc.edu/biomed/genedoc accessed on 18 November 2020) software was used to manually adjust the amino acid sequence in the SCL9 domain. PeSCL9 proteins were subjected to conserved base sequence analysis by MEME in November 2020 (http:/ / meme.nbcr.net/meme/cgibin/meme.cgi accessed on 18 November 2020) with default parameters, and the largest base sequence parameters of 20 [70]; the results were visualized using TBtools in March 2021. The psRNATarget website (http:/ / plantgrn.noble.org/psRNATarget/ accessed on 13 December 2020) was used to predict miRNAs that may regulate SCL9 genes in December 2020. To find potentially cleaved targets, the CleaveLand4 (v4.5) pipeline was used [71]. All alignments with a category $\leq 2$ and a $p$-values $\leq 0.05$ were considered candidate targets. The degradome and sRNA data were obtained from the laboratory (Accession Numbers PRJNA498391 and PRJNA498400) [44].

\subsection{Expression Vector Construction}

The expression vectors were constructed according to the Gateway Technology Protocol (Invitrogen, Carlsbad, CA, USA). For transient expression assays, the coding region of each gene, without the stop codons, was cloned into $\mathrm{pCR}^{\mathrm{TM}} 8 / \mathrm{GW} / \mathrm{TOPO}$ (Invitrogen, Carlsbad, CA, USA) to generate an entry clone. Then we transformed into competent E.coli cells, and choose a positive transformant and isolate plasmid DNA. We generated an expression vector by performing an LR recombination reaction between the entry clone and P2GWF7.0 vector, with a C-terminus of the green fluorescent protein (GFP) under the control of CaMV 35S promoter. The mature sequences of miR396a and miR396c were obtained from the sRNA data. Specific primers (Table S5) were used to amplify the precursor sequence of miR396a/c from the genomic DNA. The sequences were cloned into the overexpression vector $\mathrm{pH} 35 \mathrm{GS}$ under the control of the $35 \mathrm{~S}$ promoter using the ClonExpress II 
One Step Cloning Kit (Vazyme, Nan Jing, China). The vectors were then transformed into competent E.coli cells and used for the next experiments.

\subsection{Transient Expression Assays}

Protoplast isolation and polyethylene glycol (PEG)-mediated transformation were performed using the method of our laboratory, with minor changes [72]. Briefly, the $100 \mu \mathrm{g}$ 35S::miR396a/c plasmid was transferred into the $1 \mathrm{~mL}$ protoplast, and cultured at $20-25^{\circ} \mathrm{C}$ in darkness for $16 \mathrm{~h}$. The experiment was repeated three times. Total RNA was extracted by the method described above for analysis of gene expression levels. At the same time, the constructed transient expression vector was transformed into protoplasts. After $16 \mathrm{~h}$ of dark culture, the GFP fluorescence signal was observed to produce $509 \mathrm{~nm}$ green fluorescence under excitation with $488 \mathrm{~nm}$ blue light using a fluorescence microscope (Carl Zeiss, Jena, Germany). The data represent three independent experiments.

\subsection{Statistical Analysis}

All experiments were repeated at least three times. The RT-qPCR raw data were calculated according to the $2^{-\Delta \Delta \mathrm{Ct}}$ method. Statistical significance of differences was compared by the Student's $t$ test. “*” for $p<0.05$; “**” for $p<0.01$; “***” for $p<0.001$ were known as significant. Data were plotted as means $\pm \mathrm{SE}$. The error bars represent the mean \pm SE. GraphPad prism software (v.7.0) was used to generate graphs.

\section{Conclusions}

The present study analyzed, the role of the SCL9 subfamily in adventitious root of Populus. The results enrich our knowledge of the GRAS family of transcription factors in poplar, and further exploring SCL9, an important member of the GRAS transcription factor family, to provide a reference for research on the function of plant growth and development. Future studies on the poplar adventitious root formation mechanism will provide further theoretical support.

Supplementary Materials: The following are available online at https:/ /www.mdpi.com/article/ 10.3390/plants10071338/s1, Table S1: analysis of the protein structure encoded by six SCL9 branch genes in Populus, Table S2: Cis-elements analyses of the PeSCL9 genes promoter regions, Table S3: analyses the motifs in PeSCL9 proteins from the MEME website, Table S4: comparison of PeSCL9 with miRNA matching sites of 'Nanlin895' poplar, Table S5: primer sequences.

Author Contributions: Conceptualization, M.X.; methodology, L.X.; validation, M.Z., and H.Q.; formal analysis, T.S.; writing—original draft preparation, M.Z.; writing — review and editing, M.X.; funding acquisition, M.X. All authors have read and agreed to the published version of the manuscript.

Funding: This research was funded by grants from the National Natural Science Foundation of China (31971679; 31570671), the Natural Science Foundation of the Jiangsu Higher Education Institutions of China (19KJB180001) and the Priority Academic Program Development of Jiangsu Higher Education Institutions (PAPD).

Data Availability Statement: The latest protein sequences file of Populus deltoides genome was downloaded from Phytozome (v.12.1) in March 2021 (https://phytozome.jgi.doe.gov/pz/portal. html). The degradome were deposited in the Sequence Read Archive (SRA) database of the NCBI under accession number PRJNA498391. The sRNA-seq data submitted to SRA database under accession number PRJNA498400.

Conflicts of Interest: The authors declare no conflict of interest.

\section{References}

1. Todaro, L.; Russo, D.; Cetera, P.; Milella, L. Effects of thermo-vacuum treatment on secondary metabolite content and antioxidant activity of poplar (Populus nigra L.) wood extracts. Ind. Crop. Prod. 2017, 109, 384-390. [CrossRef]

2. Dash, M.; Yordanov, Y.S.; Georgieva, T.; Tschaplinski, T.J.; Yordanova, E.; Busov, V. Poplar PtabZIP1-like enhances lateral root formation and biomass growth under drought stress. Plant J. 2017, 89, 692-705. [CrossRef] [PubMed] 
3. Legue, V.; Rigal, A.; Bhalerao, R.P. Adventitious root formation in tree species: Involvement of transcription factors. Physiol. Plant. 2014, 151, 192-198. [CrossRef] [PubMed]

4. Ma, D.; Reichelt, M.; Yoshida, K.; Gershenzon, J.; Constabel, C.P. Two R2R3-MYB proteins are broad repressors of flavonoid and phenylpropanoid metabolism in poplar. Plant J. 2018, 96, 949-965. [CrossRef] [PubMed]

5. Rigal, A.; Yordanov, Y.S.; Perrone, I.; Karlberg, A.; Tisserant, E.; Bellini, C.; Busov, V.B.; Martin, F.; Kohler, A.; Bhalerao, R.; et al. The AINTEGUMENTA LIKE1 Homeotic Transcription Factor PtAIL1 Controls the Formation of Adventitious Root Primordia in Poplar. Plant Physiol. 2012, 160, 1996-2006. [CrossRef]

6. Wang, J.; Zhou, H.; Zhao, Y.; Sun, P.; Tang, F.; Song, X.; Lu, M.-Z. Characterization of poplar growth-regulating factors and analysis of their function in leaf size control. BMC Plant Biol. 2020, 20. [CrossRef] [PubMed]

7. Liu, D.; Song, Y.; Chen, Z.; Yu, D. Ectopic expression of miR396 suppresses GRF target gene expression and alters leaf growth in Arabidopsis. Physiol. Plant. 2009, 136, 223-236. [CrossRef]

8. Llave, C.; Kasschau, K.D.; Rector, M.A.; Carrington, J.C. Endogenous and Silencing-Associated Small RNAs in Plants. Plant Cell 2002, 14, 1605-1619. [CrossRef]

9. Sunkar, R.; Zhu, J.-K. Novel and Stress-Regulated MicroRNAs and Other Small RNAs from Arabidopsis. Plant Cell 2004, 16, 2001-2019. [CrossRef]

10. Peng, J.; Carol, P.; Richards, D.E.; King, K.E.; Cowling, R.J.; Murphy, G.P.; Harberd, N.P. The Arabidopsis GAI gene defines a signaling pathway that negatively regulates gibberellin responses. Genes Dev. 1997, 11, 3194-3205. [CrossRef]

11. Silverstone, A.L.; Ciampaglio, C.N.; Sun, T. The Arabidopsis RGA gene encodes a transcriptional regulator repressing the gibberellin signal transduction pathway. Plant Cell 1998, 10, 155-169. [CrossRef] [PubMed]

12. Di Laurenzio, L.; Wysocka-Diller, J.; Malamy, J.E.; Pysh, L.; Helariutta, Y.; Freshour, G.; Hahn, M.G.; Feldmann, K.A.; Benfey, P.N. The SCARECROW Gene Regulates an Asymmetric Cell Division That Is Essential for Generating the Radial Organization of the Arabidopsis Root. Cell 1996, 86, 423-433. [CrossRef]

13. Pysh, L.D.; Wysocka-Diller, J.W.; Camilleri, C.; Bouchez, D.; Benfey, P.N. The GRAS gene family in Arabidopsis: Sequence characterization and basic expression analysis of the SCARECROW-LIKE genes. Plant J. Cell Mol. Biol. 1999, 18, 111-119. [CrossRef] [PubMed]

14. Heery, D.M.; Kalkhoven, E.; Hoare, S.; Parker, M.G. A signature motif in transcriptional co-activators mediates binding to nuclear receptors. Nature 1997, 387, 733-736. [CrossRef] [PubMed]

15. Bolle, C. The role of GRAS proteins in plant signal transduction and development. Planta 2004, 218, 683-692. [CrossRef]

16. Lee, H.; Kim, B.; Song, S.-K.; Heo, J.-O.; Yu, N.-I.; Lee, S.A.; Kim, M.; Kim, D.G.; Sohn, S.O.; Lim, C.E.; et al. Large-scale analysis of the GRAS gene family in Arabidopsis thaliana. Plant Mol. Biol. 2008, 67, 659-670. [CrossRef] [PubMed]

17. Liu, M.; Huang, L.; Ma, Z.; Sun, W.; Wu, Q.; Tang, Z.; Bu, T.; Li, C.; Chen, H. Genome-wide identification, expression analysis and functional study of the GRAS gene family in Tartary buckwheat (Fagopyrum tataricum). BMC Plant Biol. 2019, 19. [CrossRef]

18. Sun, X.; Jones, W.T.; Rikkerink, E.H.A. GRAS proteins: The versatile roles of intrinsically disordered proteins in plant signalling. Biochem. J. 2012, 442, 1-12. [CrossRef]

19. Zhang, B.; Liu, J.; Yang, Z.E.; Chen, E.Y.; Zhang, C.J.; Zhang, X.Y.; Li, F.G. Genome-wide analysis of GRAS transcription factor gene family in Gossypium hirsutum L. BMC Genom. 2018, 19. [CrossRef]

20. Tian, C.G.; Wan, P.; Sun, S.H.; Li, J.Y.; Chen, M.S. Genome-wide analysis of the GRAS gene family in rice and Arabidopsis. Plant Mol. Biol. 2004, 54, 519-532. [CrossRef]

21. Bolle, C.; Koncz, C.; Chua, N.H. PAT1, a new member of the GRAS family, is involved in phytochrome A signal transduction. Genes Dev. 2000, 14, 1269-1278.

22. Heo, J.-O.; Chang, K.S.; Kim, I.A.; Lee, M.-H.; Lee, S.A.; Song, S.-K.; Lee, M.M.; Lim, J. Funneling of gibberellin signaling by the GRAS transcription regulator SCARECROW-LIKE 3 in the Arabidopsis root. Proc. Natl. Acad. Sci. USA 2011, 108, $2166-2171$. [CrossRef]

23. Zhang, Z.-L.; Ogawa, M.; Fleet, C.M.; Zentella, R.; Hu, J.; Heo, J.-O.; Lim, J.; Kamiya, Y.; Yamaguchi, S.; Sun, T.-p. SCARECROWLIKE 3 promotes gibberellin signaling by antagonizing master growth repressor DELLA in Arabidopsis. Proc. Natl. Acad. Sci. USA 2011, 108, 2160-2165. [CrossRef] [PubMed]

24. Yoshida, H.; Hirano, K.; Sato, T.; Mitsuda, N.; Nomoto, M.; Maeo, K.; Koketsu, E.; Mitani, R.; Kawamura, M.; Ishiguro, S.; et al. DELLA protein functions as a transcriptional activator through the DNA binding of the INDETERMINATE DOMAIN family proteins. Proc. Natl. Acad. Sci. USA 2014, 111, 7861-7866. [CrossRef] [PubMed]

25. Cui, H.; Levesque, M.P.; Vernoux, T.; Jung, J.W.; Paquette, A.J.; Gallagher, K.L.; Wang, J.Y.; Blilou, I.; Scheres, B.; Benfey, P.N. An evolutionarily conserved mechanism delimiting SHR movement defines a single layer of endodermis in plants. Science 2007, 316, 421-425. [CrossRef] [PubMed]

26. Helariutta, Y.; Fukaki, H.; Wysocka-Diller, J.; Nakajima, K.; Jung, J.; Sena, G.; Hauser, M.T.; Benfey, P.N. The SHORT-ROOT gene controls radial patterning of the Arabidopsis root through radial signaling. Cell 2000, 101, 555-567. [CrossRef]

27. Sabatini, S.; Heidstra, R.; Wildwater, M.; Scheres, B. SCARECROW is involved in positioning the stem cell niche in the Arabidopsis root meristem. Genes Dev. 2003, 17, 354-358. [CrossRef]

28. Morohashi, K.; Minami, M.; Takase, H.; Hotta, Y.; Hiratsuka, K. Isolation and Characterization of a Novel GRAS Gene That Regulates Meiosis-associated Gene Expression. J. Biol. Chem. 2003, 278, 20865-20873. [CrossRef]

29. Cenci, A.; Rouard, M. Evolutionary Analyses of GRAS Transcription Factors in Angiosperms. Front. Plant Sci. 2017, 8. [CrossRef] 
30. Xu, K.; Chen, S.; Li, T.; Ma, X.; Liang, X.; Ding, X.; Liu, H.; Luo, L. OsGRAS23, a rice GRAS transcription factor gene, is involved in drought stress response through regulating expression of stress-responsive genes. BMC Plant Biol. 2015, 15. [CrossRef]

31. Chen, K.; Li, H.; Chen, Y.; Zheng, Q.; Li, B.; Li, Z. TaSCL14, a Novel Wheat (Triticum aestivum L.) GRAS Gene, Regulates Plant Growth, Photosynthesis, Tolerance to Photooxidative Stress, and Senescence. J. Genet. Genom. 2015, 42, 21-32. [CrossRef] [PubMed]

32. Fode, B.; Siemsen, T.; Thurow, C.; Weigel, R.; Gatz, C. The Arabidopsis GRAS Protein SCL14 Interacts with Class II TGA Transcription Factors and Is Essential for the Activation of Stress-Inducible Promoters. Plant Cell 2008, 20, 3122-3135. [CrossRef] [PubMed]

33. Huang, L.-J.; Li, N.; Thurow, C.; Wirtz, M.; Hell, R.; Gatz, C. Ectopically expressed glutaredoxin ROXY19 negatively regulates the detoxification pathway in Arabidopsis thaliana. BMC Plant Biol. 2016, 16. [CrossRef] [PubMed]

34. Köster, J.; Thurow, C.; Kruse, K.; Meier, A.; Iven, T.; Feussner, I.; Gatz, C. Xenobiotic- and Jasmonic Acid-Inducible Signal Transduction Pathways Have Become Interdependent at the Arabidopsis CYP81D11 Promoter. Plant Physiol. 2012, 159, 391-402. [CrossRef] [PubMed]

35. Carlsbecker, A.; Lee, J.-Y.; Roberts, C.J.; Dettmer, J.; Lehesranta, S.; Zhou, J.; Lindgren, O.; Moreno-Risueno, M.A.; Vatén, A.; Thitamadee, S.; et al. Cell signalling by microRNA165/6 directs gene dose-dependent root cell fate. Nature 2010, 465, 316-321. [CrossRef] [PubMed]

36. Chen, Q.J.; Deng, B.H.; Gao, J.; Zhao, Z.Y.; Chen, Z.L.; Song, S.R.; Wang, L.; Zhao, L.P.; Xu, W.P.; Zhang, C.X.; et al. A miRNA-Encoded Small Peptide, vvi-miPEP171d1, Regulates Adventitious Root Formation. Plant Physiol. 2020, 183, 656-670. [CrossRef]

37. Curaba, J.; Talbot, M.; Li, Z.; Helliwell, C. Over-expression of microRNA171 affects phase transitions and floral meristem determinancy in barley. BMC Plant Biol. 2013, 13, 6. [CrossRef]

38. Hofferek, V.; Mendrinna, A.; Gaude, N.; Krajinski, F.; Devers, E.A. MiR171h restricts root symbioses and shows like its target NSP2 a complex transcriptional regulation in Medicago truncatula. BMC Plant Biol. 2014, 14. [CrossRef]

39. Liu, X.; Widmer, A. Genome-wide Comparative Analysis of the GRAS Gene Family in Populus, Arabidopsis and Rice. Plant. Mol. Biol. Report. 2014, 32, 1129-1145. [CrossRef]

40. Fan, H.; Xuan, L.; Xu, M. Cloning, Expression and Subcellular Localization of PeHAM1 and PeHAM2 Genes in Poplar. Mol. Plant Breed. 2019, 17, 2476-2485. [CrossRef]

41. Cai, H.; Xuan, L.; Xu, L.-A.; Huang, M.-R.; Xu, M. Identification and characterization of nine PAT1 branch genes in poplar. Plant Growth Regul. 2017, 81, 355-364. [CrossRef]

42. Liu, S.; Xuan, L.; Xu, L.-A.; Huang, M.; Xu, M. Molecular cloning, expression analysis and subcellular localization of four DELLA genes from hybrid poplar. Springerplus 2016, 5. [CrossRef]

43. Xuan, L.; Xu, M.; Chen, C.; Yang, C.; Xu, L.a.; Huang, M. Identification and characterization of three PeSHRs and one PeSCR involved in adventitious root development of Populus. Plant Cell Tissue Organ. Cult. 2014, 117, 253-264. [CrossRef]

44. Cai, H.; Yang, C.; Liu, S.; Qi, H.; Wu, L.; Xu, L.A.; Xu, M. MiRNA-target pairs regulate adventitious rooting in Populus: A functional role for miR167a and its target Auxin response factor 8. Tree Physiol. 2019, 39, 1922-1936. [CrossRef] [PubMed]

45. Sedlacek, J.; Cortés, A.J.; Wheeler, J.; Bossdorf, O.; Hoch, G.; Klápště, J.; Lexer, C.; Rixen, C.; Wipf, S.; Karrenberg, S.; et al. Evolutionary potential in the Alpine: Trait heritabilities and performance variation of the dwarf willow Salix herbacea from different elevations and microhabitats. Ecol. Evol. 2016, 6, 3940-3952. [CrossRef] [PubMed]

46. Ma, H.-S.; Liang, D.; Shuai, P.; Xia, X.-L.; Yin, W.-L. The salt- and drought-inducible poplar GRAS protein SCL7 confers salt and drought tolerance in Arabidopsis thaliana. J. Exp. Bot. 2010, 61, 4011-4019. [CrossRef]

47. Wang, J.; Andersson-Gunnerås, S.; Gaboreanu, I.; Hertzberg, M.; Tucker, M.R.; Zheng, B.; Leśniewska, J.; Mellerowicz, E.J.; Laux, T.; Sandberg, G.; et al. Reduced Expression of the SHORT-ROOT Gene Increases the Rates of Growth and Development in Hybrid Poplar and Arabidopsis. PLoS ONE 2011, 6, e28878. [CrossRef] [PubMed]

48. Vielba, J.M.; Diaz-Sala, C.; Ferro, E.; Rico, S.; Lamprecht, M.; Abarca, D.; Ballester, A.; Sanchez, C. CsSCL1 is differentially regulated upon maturation in chestnut microshoots and is specifically expressed in rooting-competent cells. Tree Physiol. 2011, 31, 1152-1160. [CrossRef]

49. D'Alessandro, S.; Ksas, B.; Havaux, M. Decoding $\beta$-Cyclocitral-Mediated Retrograde Signaling Reveals the Role of a Detoxification Response in Plant Tolerance to Photooxidative Stress. Plant Cell 2018, 30, 2495-2511. [CrossRef]

50. Chen, H.Y.; Hsieh, E.J.; Cheng, M.C.; Chen, C.Y.; Hwang, S.Y.; Lin, T.P. ORA47 (octadecanoid-responsive AP2/ERF-domain transcription factor 47) regulates jasmonic acid and abscisic acid biosynthesis and signaling through binding to a novel cis-element. New Phytol. 2016, 211, 599-613. [CrossRef] [PubMed]

51. Nakashima, K.; Yamaguchi-Shinozaki, K.; Shinozaki, K. The transcriptional regulatory network in the drought response and its crosstalk in abiotic stress responses including drought, cold, and heat. Front. Plant Sci. 2014, 5. [CrossRef] [PubMed]

52. Sun, X.; Xue, B.; Jones, W.T.; Rikkerink, E.; Dunker, A.K.; Uversky, V.N. A functionally required unfoldome from the plant kingdom: Intrinsically disordered N-terminal domains of GRAS proteins are involved in molecular recognition during plant development. Plant Mol. Biol. 2011, 77, 205-223. [CrossRef] [PubMed]

53. Liu, W.; Zhou, Y.; Li, X.; Wang, X.; Dong, Y.; Wang, N.; Liu, X.; Chen, H.; Yao, N.; Cui, X.; et al. Tissue-Specific Regulation of Gma-miR396 Family on Coordinating Development and Low Water Availability Responses. Front. Plant Sci $2017,8,1112$. [CrossRef] 
54. Guo, P.; Wen, J.; Yang, J.; Ke, Y.; Wang, M.; Liu, M.; Ran, F.; Wu, Y.; Li, P.; Li, J.; et al. Genome-wide survey and expression analyses of the GRAS gene family in Brassica napus reveals their roles in root development and stress response. Planta 2019, 250, 1051-1072. [CrossRef]

55. Hakoshima, T. Structural basis of the specific interactions of GRAS family proteins. FEBS Lett. 2018, 592, 489-501. [CrossRef] [PubMed]

56. Guo, Y.; We, H.; Li, X.; Li, Q.; Zhao, X.; Duan, X.; An, Y.; Lv, W.; An, H. Identification and expression of GRAS family genes in maize (Zea mays L.). PLoS ONE 2017, 12. [CrossRef]

57. Liu, N.; Tu, L.; Tang, W.; Gao, W.; Lindsey, K.; Zhang, X. Small RNA and degradome profiling reveals a role for miRNAs and their targets in the developing fibers of Gossypium barbadense. Plant J. 2014, 80, 331-344. [CrossRef]

58. Rodriguez, R.E.; Schommer, C.; Palatnik, J.F. Control of cell proliferation by microRNAs in plants. Curr. Opin. Plant. Biol. 2016, 34, 68-76. [CrossRef]

59. Axtell, M.J.; Bartel, D.P. Antiquity of microRNAs and their targets in land plants. Plant Cell 2005, 17, 1658-1673. [CrossRef]

60. Peng, T.; Qiao, M.; Liu, H.; Teotia, S.; Zhang, Z.; Zhao, Y.; Wang, B.; Zhao, D.; Shi, L.; Zhang, C.; et al. A Resource for Inactivation of MicroRNAs Using Short Tandem Target Mimic Technology in Model and Crop Plants. Mol. Plant 2018, 11, 1400-1417. [CrossRef]

61. Smoczynska, A.; Szweykowska-Kulinska, Z. MicroRNA-mediated regulation of flower development in grasses. Acta Biochim. Pol. 2016, 63, 687-692. [CrossRef]

62. Rodriguez, R.E.; Ercoli, M.F.; Debernardi, J.M.; Breakfield, N.W.; Mecchia, M.A.; Sabatini, M.; Cools, T.; De Veylder, L.; Benfey, P.N.; Palatnik, J.F. MicroRNA miR396 Regulates the Switch between Stem Cells and Transit-Amplifying Cells in Arabidopsis Roots. Plant Cell 2015, 27, 3354-3366. [CrossRef]

63. Quan, M.; Du, Q.; Xiao, L.; Lu, W.; Wang, L.; Xie, J.; Song, Y.; Xu, B.; Zhang, D. Genetic architecture underlying the lignin biosynthesis pathway involves noncoding RNAs and transcription factors for growth and wood properties in Populus. Plant Biotechnol. J. 2019, 17, 302-315. [CrossRef] [PubMed]

64. Kelleher, C.T.; Wilkin, J.; Zhuang, J.; Cortés, A.J.; Quintero, Á.L.P.; Gallagher, T.F.; Bohlmann, J.; Douglas, C.J.; Ellis, B.E.; Ritland, K. SNP discovery, gene diversity, and linkage disequilibrium in wild populations of Populus tremuloides. Tree Genet. Genomes 2012, 8, 821-829. [CrossRef]

65. Cortés, A.J.; Restrepo-Montoya, M.; Bedoya-Canas, L.E. Modern Strategies to Assess and Breed Forest Tree Adaptation to Changing Climate. Front. Plant Sci. 2020, 11. [CrossRef] [PubMed]

66. Xu, M.; Zhang, B.; Su, X.; Zhang, S.; Huang, M. Reference gene selection for quantitative real-time polymerase chain reaction in Populus. Anal. Biochem. 2011, 408, 337-339. [CrossRef]

67. Chen, C.; Chen, H.; Zhang, Y.; Thomas, H.R.; Frank, M.H.; He, Y.; Xia, R. TBtools: An Integrative Toolkit Developed for Interactive Analyses of Big Biological Data. Mol. Plant 2020,13, 1194-1202. [CrossRef] [PubMed]

68. Lescot, M. PlantCARE, a database of plant cis-acting regulatory elements and a portal to tools for in silico analysis of promoter sequences. Nucleic Acids Res. 2002, 30, 325-327. [CrossRef]

69. Kumar, S.; Stecher, G.; Li, M.; Knyaz, C.; Tamura, K. MEGA X: Molecular Evolutionary Genetics Analysis across Computing Platforms. Mol. Biol. Evol. 2018, 35, 1547-1549. [CrossRef]

70. Bailey, T.L.; Williams, N.; Misleh, C.; Li, W.W. MEME: Discovering and analyzing DNA and protein sequence motifs. Nucleic Acids Res. 2006, 34, W369-W373. [CrossRef]

71. Addo-Quaye, C.; Miller, W.; Axtell, M.J. CleaveLand: A pipeline for using degradome data to find cleaved small RNA targets. Bioinformatics 2009, 25, 130-131. [CrossRef] [PubMed]

72. Tan, B.; Xu, M.; Chen, Y.; Huang, M. Transient expression for functional gene analysis using Populus protoplasts. Plant Cell Tissue Organ. Cult. 2013, 114, 11-18. [CrossRef] 